\title{
Association between serum ferritin and lipid peroxidation in hemodialysis patients
}

\section{Authors}

Liliana M. Pedruzzi ${ }^{1}$

Ludmila Ferreira Medeiros de França Cardozo'

Renata F. Medeiros ${ }^{1}$

Milena B. Stockler-Pinto ${ }^{1}$

Denise Mafra ${ }^{1}$

1 Universidade Federal Fluminense (UFF).
Submitted on: 10/23/2014. Approved on: 02/10/2015.

Correspondence to: Liliana M. Pedruzzi. Fluminense Federal University. Rua Lídio Machado, no 559, apto 401, Santo Andrezinho, Castelo ES, Brasil.

CEP: 29360-000

E-mail: lilianapedruzzi@yahoo. com.br

Tel: (28) 9 9946-9930.

CAPES, Conselho Nacional de

Pesquisa (CNPq) e Fundação de

Amparo à Pesquisa do Estado do Rio de Janeiro (FAPERJ).

\section{Abstract}

Introduction: Iron supplementation is one of the recommendations found in patients with chronic kidney disease (CKD), however, an overload of this mineral can contribute to oxidative stress, a condition closely related to the cardiovascular risk in these patients, as well as disease progression. Objective: The objective of this study was to investigate whether ferritin levels are associated with oxidative stress marker MDA in patients on hemodialysis (HD). Methods: Twenty HD patients $(55.0 \pm 15.2$ years, time of dialysis $76.5 \pm 46.3$ months, BMI 23.6 $\left.\pm 3.0 \mathrm{~kg} / \mathrm{m}^{2}\right)$ were compared with 11 healthy subjects $(50.9 \pm 8.0$ years, BMI $23.8 \pm 1.9 \mathrm{~kg} / \mathrm{m}^{2}$ ). Malondialdehyde (MDA) was measured by reaction with thiobarbituric acid and routine biochemical data were obtained from medical records. Results: MDA levels were significantly higher in HD patients compared to the control group (13.2 $\pm 5.3 \mathrm{nmol} / \mathrm{mL}$ vs. $5.1 \pm 2.7 \mathrm{nmol} / \mathrm{mL}$, $p<0.01)$. Twelve patients $(60 \%)$ had ferritin values greater than the $500 \mathrm{ng} /$ $\mathrm{mL}$ and there was a positive correlation between ferritin and MDA in HD ( $\mathrm{r}$ $=0.66, p=0.005, \mathrm{n}=17$ ) patients. Conclusion: The excess iron stores in HD patients results in increased lipid peroxidation, and consequently contributes to increased oxidative stress in these patients.

Keywords: ferritins; malondialdehyde; oxidative stress; renal dialysis.

\section{INTRODUCTION}

Oxidative stress is a common condition in chronic kidney disease (CKD) patients, and it is associated with decreased renal function, ${ }^{1}$ in addition to being an important etiological factor in atherogenesis, which contributes to increased cardiovascular risk in these patients. ${ }^{2}$ In order to investigate the possible changes that can cause oxidative stress in different diseases, the identification of its biomarkers is critical. Among these, the most used is the malondialdehyde (MDA), a short chain aldehyde resulting from the oxidation of polyunsaturated fatty acids, i.e., a product derived from lipid peroxidation, which can be measured by the reaction with thiobarbituric acid (TBA). ${ }^{3}$ It is considered a suitable oxidative stress marker in CKD, having an inverse relation to renal function and positive correlation with uremic toxins. ${ }^{3-5}$

There are many factors that lead to oxidative stress in CKD, among which we can list proteinuria, associated diseases, uremic toxins and hemodialysis (HD). ${ }^{6}$ Furthermore, ferritin - an iron store globular protein, also seems to be another factor contributing to oxidative stress in these pacients. ${ }^{7,8}$

Iron supplementation is a common recommendation for patients with 
kidney disease; however, too much iron can act as a pro-oxidant factor, thereby contributing to the oxidation of molecules such as lipid peroxidation..$^{9,10}$ This is important, given that anemia is a common complication observed in renal patients and the administration of human recombinanterythropoietin (EPO) and intravenous iron are recommended by the Kidney Disease Outcomes Quality Initiative (KDOQI) Clinical Practice Guidelines. ${ }^{11}$ Therefore, studies about the possible link between oxidative stress and iron stores in patients on HD are important, since high levels of iron can aggravate the oxidative stress already present in these patients. Thus, the goal of this study was to investigate whether ferritin levels are associated with MDA in patients on HD.

\section{Materials AND Methods}

\section{SUBJECTS}

We studied 20 chronic renal failure patients on hemodialysis treatment (mean age $55.0 \pm 15.2$ years, mean time on dialysis for $76.5 \pm 46.3$ months) in the Nephrology Clinic, Niterói, RJ, Brazil. Patient selection was based on a convenience sample strategy. The patients underwent three HD sessions weekly with mean duration of 4 hours, blood flow higher than $250 \mathrm{ml} / \mathrm{min}$ and dialysate flow of $500 \mathrm{ml} / \mathrm{min}$. All eligible subjects were previously informed about the study and the use of biological material for carrying out the study and were asked to sign the consent form. The study protocol was reviewed and approved by the Ethics Committee of the School of Medicine/HUAP - Fluminense Federal University as project addendum No. 018/09. Eleven subjects without CKD (five men, mean age $50.9 \pm 8.0$ years, BMI $23.8 \pm 1.9 \mathrm{~kg} / \mathrm{m} 2$ ), without the use of any medication or pre-existing disease made up the control group.

The study included men and women over 18 years of age, from the first and second shifts in HD treatment for at least 6 months and with arteriovenous fistula (AVF) for vascular access. Patients with inflammatory diseases, neoplastic disorders, AIDS, autoimmune disease, smokers, patients using catabolizing drugs and antioxidant vitamin supplements were taken off the study.

\section{NUTRITIONAL ASSESSMENT}

The following anthropometric parameters were measured: body weight, height and waist circumference. Weight measurement was carried out by means of a calibrated Filizola scale with a maximum capacity of $150 \mathrm{~kg}$ and subdivisions every 100 grams. The participant was positioned standing in the center of the scale, without shoes on. We used a stadiometer attached to the scale to measure the subject's height, as per referred to above, being the participant standing without shoes on, heels tucked together, back straight and arms extended at the sides of the body. The body mass index (BMI) was calculated from the dry weight and the height squared ratio. ${ }^{12}$

For measuring waist circumference (WC), the patient remained standing and with the aid of a measuring tape the participant was surrounded in the natural waist line, in the narrowest area between the chest and the hip in midpoint between the last rib and the iliac crest. The reading was taken during expiration. ${ }^{13}$ The risk of complications associated with obesity is high when WC values are greater than $94 \mathrm{~cm}$ for men and $80 \mathrm{~cm}$ for women and is considered very high when the values are greater than $102 \mathrm{~cm}$ for men and $88 \mathrm{~cm}$ for women. ${ }^{14}$ The measurements were made after the dialysis session by a trained member of the staff.

\section{BIOCHEMICAL PARAMETERS}

Results of the biochemical routine tests: albumin, urea, creatinine, phosphorus, parathyroid hormone (PTH), hemoglobin $(\mathrm{Hb})$, hematocrit $(\mathrm{Ht})$, ferritin, iron $(\mathrm{Fe})$ and transferrin saturation (SatFe) were obtained from medical records.

For HD patients, the diagnosis of anemia was based only on $\mathrm{Hb}$ values, with values of $11-13 \mathrm{~g} / \mathrm{dL}$ considered normal. For Fe and transferrin saturation (SatFe), reference values are $50-150 \mathrm{mcg} / 100 \mathrm{~mL}$ and $20-40 \%$, respectively. Ferritin values between 200 and $500 \mathrm{ng} / \mathrm{mL}$ were considered adequate. ${ }^{11}$

\section{BLOOd LEVELS}

Blood samples were collected from each participant in the control group in the morning 
after 12 hours fasting before starting the $\mathrm{HD}$ session. In patients undergoing $\mathrm{HD}$, the biological material was collected under the same conditions and before the dialysis session. Blood was collected in tubes $\left(\right.$ Vacutainer $\left.^{\circledR}\right)$ containing EDTA as an anticoagulant agent. Plasma was separated (15 minutes, $\left.3000 \mathrm{rpm}, 4^{\circ} \mathrm{C}\right)$ and stored at $-80^{\circ} \mathrm{C}$ for later analysis.

Tumor necrosis factor (TNF- $\alpha$ ) serum levels were measured by using Cayman ELISA kit TNF- $\alpha$ (human) EIA Kit ${ }^{\circledR}$ - Cayman Chemical Company (Ann Arbor, MI, USA). In order to measure interleukin-6 (IL-6) and C-reactive protein (CRP), we used commercial kits: DuoSet ${ }^{\circledR}$ ELISA Development System - R \& D Systems (Minneapolis, MN, USA).

\section{Malondialdehyde Measurement}

Lipid peroxidation was estimated by the reaction between MDA and thiobarbituric acid using the modified Ohkawa method. ${ }^{15}$

In Eppendorf tubes we added $70 \mu \mathrm{L}$ of diluted MDA standards, $35 \mu \mathrm{L}$ of $8.1 \%$ SDS (w/v), 385 $\mu \mathrm{L}$ of $1 \%$ phosphoric acid $(\mathrm{v} / \mathrm{v}), 70 \mu \mathrm{L}$ of plasma from each patient and $210 \mu \mathrm{L}$ of thiobarbituric acid (TBA) $0.6 \%(\mathrm{w} / \mathrm{v})$. The Eppendorf tubes were vigorously shaken and then taken to a dry hot bath at $95^{\circ} \mathrm{C}$ for 1 hour. After this period the Eppendorf tubes were centrifuged at 4,000 rpm for 5 minutes, the supernatant was separated and the absorbance measured in a Synergy H1M $\left(\right.$ Biotek $^{\circledR}$ ) microplate reader at $532 \mathrm{~nm}$. Plasma levels of MDA are expressed as nanomoles per milliliter.

\section{StATISTICAL ANALYSIS}

The normal distribution of the data was determined using the Shapiro-Wilk test. Data is expressed as mean \pm standard deviation, median (interquartile range), categorical data is presented as percentage. Comparisons between groups were performed using the two-tailed unpaired Student $t$-Test for parametric variables, and the Mann-Whitney test for the nonparametric variables. The correlation between variables of interest was performed using the Pearson or Spearman correlation coefficient, as appropriate. Multiple regression analysis was used to find which possible parameters influence the MDA levels. Tests were fixed at a 5\% ( $p<$ $0.05)$ significance level. Statistical analysis was performed using the SPSS 19.0 software (SPSS, Inc., Chicago, IL, USA).

\section{Results}

The biochemical parameters of the patients are depicted on Table 1. Eleven patients $(55 \%)$ had anemia $(\mathrm{Hb}<11 \mathrm{~g} / \mathrm{dL})$ and $12(60 \%)$ showed ferritin values greater than $500 \mathrm{ng} / \mathrm{ml}$. Only five patients $(25 \%)$ had ferritin levels considered ideal $(200-500 \mathrm{ng} / \mathrm{ml})$ and three patients $(15 \%)$ had values lower than the goal to be achieved (ferritin $<200 \mathrm{ng} / \mathrm{mL}$ ). In relation to the $\mathrm{Fe}$ and SatFe, 16 patients $(80 \%)$ had suitable values of Fe and $15(75 \%)$ for SatFe.

Demographic, anthropometric and laboratory characteristics of the participants are presented on Table 2. Based on the metabolic complications risk classification associated with obesity, evaluated according to the WC, 10 patients $(50 \%)$ had elevated WC values (five men and five women).

CRP levels, TNF- $\alpha$, IL- 6 and MDA were significantly higher in HD patients compared with the control group. There was a positive correlation between ferritin and MDA in HD patients $(r=0.66 ; p=0.005, n=17$, Figure 1$)$ and there was no correlation between ferritin and inflammatory markers like CRP, TNF - $\alpha$ and IL - 6. According to the regression analysis, the only variable that affected MDA levels was ferritin $(\beta=0.8 ; p=0.02)$.

\section{Discussion}

HD patients are commonly exposed to oxidative stress, which is an important cardiovascular risk factor; and one of the factors that has been associated with this condition in patients with CKD is ferritin. In fact, our results showed a positive association between serum ferritin and MDA in the patients studied. So it seems that ferritin can aggravate oxidative stress in patients 
TABLE 1

BIOCHEMICAL PROFILE OF THE PATIENTS STUDIED

\begin{tabular}{lcc}
\hline Variables & Results & Normality \\
\hline Albumin (g/dL) & $3.9 \pm 0.6$ & $>3.8$ \\
Pre-HD urea (mg/dL) & $142.1 \pm 27.7$ & - \\
Post-HD urea (mg/dL) & $43.8 \pm 16.5$ & - \\
Creatinine (mg/dL) & $8.4 \pm 2.6$ & - \\
Potassium (mg/dL) & $5.4 \pm 0.5$ & $3.5-5.5$ \\
Phosphorus (mg/dL) & $5.2 \pm 1.2$ & $3.5-5.5$ \\
Calcium (mg/dL) & $8.9 \pm 0.5$ & $8.4-9.5$ \\
PTH (pg/mL) & $288(188.2-452.2)$ & $150-300$ \\
Hemoglobin (g/dL) & $10.6 \pm 1.9$ & $11-13$ \\
Hematocrit (\%) & $31.5 \pm 6.0$ & - \\
Ferritin (ng/mL) & $613.1 \pm 396.6$ & 200 e 500 \\
SatFe (\%) & $28.2 \pm 7.4$ & $\geq 20$ \\
Ferro (mcg/100mL) & $79.1 \pm 30.5$ & $50-150$ \\
KtN & $1.6 \pm 0.4$ & $>1.2$ \\
Weight gain between & $3.2(1-5.9)$ & \\
dialysis sessions (kg) & & \\
\hline HD: Hemodialysis; PTH: Parathyroid hormone; SatFe: Transferrin \\
saturation.
\end{tabular}

\begin{tabular}{|c|c|c|c|}
\hline Table 2 & \multicolumn{3}{|c|}{$\begin{array}{l}\text { DEMOGRAPHIC, ANTHROPOMETRIC AND } \\
\text { LABORATORIAL CHARACTERISTICS OF THE } \\
\text { PATIENTS ENROLLED IN THE STUDY }\end{array}$} \\
\hline \multicolumn{2}{|c|}{ Parameters } & $\begin{array}{l}\text { Patients on HD } \\
\qquad(\mathrm{n}=20)\end{array}$ & $\begin{array}{c}\text { Control Group } \\
(\mathrm{n}=11)\end{array}$ \\
\hline \multicolumn{2}{|c|}{ Age (years) } & $55.0 \pm 15.2$ & $51.0 \pm 7.9$ \\
\hline \multicolumn{2}{|c|}{$\mathrm{BMI}\left(\mathrm{kg} / \mathrm{m}^{2}\right)$} & $23.6 \pm 3.0$ & $23.8 \pm 1.9$ \\
\hline \multicolumn{2}{|c|}{ WC (cm) } & $91.3 \pm 11.1$ & $85.8 \pm 9.7$ \\
\hline \multicolumn{2}{|c|}{ CRP (mg/dL) } & $2.24(1.74-3.35)^{*}$ & $0.21(0.18-0.24)$ \\
\hline \multicolumn{2}{|c|}{ TNF - $\alpha(p g / m L)$} & $46.0 \pm 11.8^{* *}$ & $36.1 \pm 10.1$ \\
\hline \multicolumn{2}{|c|}{ IL - 6 (pg/dL) } & $1.64 \pm 0.62 * * *$ & $1.0 \pm 0.3$ \\
\hline \multicolumn{2}{|c|}{ MDA (nmol/mL) } & $13.2 \pm 5.3^{* * *}$ & $5.1 \pm 2.7$ \\
\hline
\end{tabular}

${ }^{*} p=0.004 ;{ }^{*} p=0.04 ;{ }^{* *} p<0.01 \mathrm{BMI}$ : body mass index; WC: waist circumference; CRP: C-reactive protein; TNF - $\alpha$ : tumor necrosis factor alpha; IL - 6: Interleukin-6; MDA: Malondialdehyde.

on HD and hence contribute to increased cardiovascular risk in these patients.

According to the National Kidney Foundation, ${ }^{11}$ there is insufficient evidence about the potential risks and benefits of high levels of ferritin. However, although some studies did not find a relationship between ferritin levels and oxidative stress markers in patients on $\mathrm{HD},{ }^{16,17}$ most of them corroborate our results. Similarly to what we found, Lim et al., ${ }^{8}$ also found a positive correlation between serum ferritin and
Figure 1. Correlation between MDA and Ferritin levels in patients on HD.

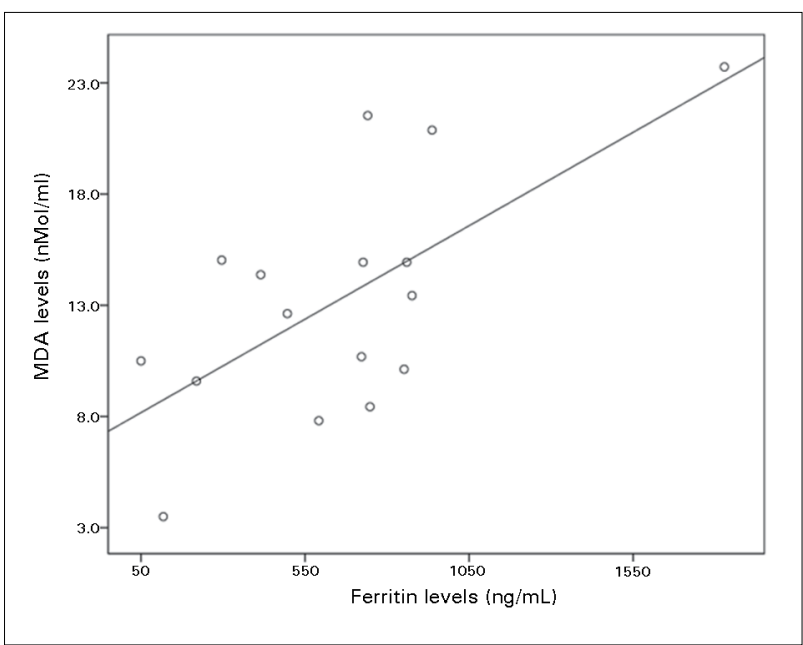

MDA plasma levels. These authors assessed 50 patients on HD who were divided in groups 1 , 2 and 3 according to baseline serum ferritin < 300, 301-600 and > $601 \mathrm{mg} / \mathrm{L}$, respectively, and further found that the MDA levels were significantly higher in the three groups of patients compared with the control group, being higher in those with ferritin levels higher than $601 \mathrm{mg} / \mathrm{L}$ and, more importantly, there was a significant increase in MDA levels after iron infusion. In our study, MDA oxidative stress marker levels were also significantly higher in HD patients compared with the control group.

Recent studies also report that high levels of ferritin are a strong predictor of lipid peroxidation in HD patients, and that lipid peroxidation markers also increase significantly after iron infusion. ${ }^{10,18}$

In a study by Wolf et al., ${ }^{19}$ the authors described a positive correlation between electronegative low density lipoprotein (LDL) cholesterol and ferritin independent of inflammation. In this study, patients were also divided according to ferritin levels $(<500$ $\mathrm{ng} / \mathrm{ml}, 500-1000 \mathrm{ng} / \mathrm{ml}$ and $>1000 \mathrm{ng} / \mathrm{mL}$ ) and those with ferritin values higher than $1000 \mathrm{ng} / \mathrm{ml}$ had high levels of electronegative LDL.

When ferritin levels are higher than $500 \mathrm{ng} /$ $\mathrm{mL}$, the decisions on whether or not to give the patient iron must be analyzed considering the response to erythropoiesis stimulating agents (ESAs), as well as $\mathrm{Hb}$ and SatFe levels and the clinical status of patients to avoid iron overload. ${ }^{11}$ 
In our study, we found high ferritin levels, higher than $500 \mathrm{ng} / \mathrm{ml}$ in average and appropriate amounts of Fe and SatFe in most patients, which leads to say that the iron reserves are high.

However, a question that should be considered on this subject is inflammation. In CKD patients the presence of inflammation leads to the socalled functional iron deficiency, characterized by normal or increased ferritin and, paradoxically, a reduced concentration of serum $\mathrm{Fe}$ and SatFe. This is because inflammation leads to increased hepatic production of hepcidin, a peptide that inhibits intestinal iron absorption and iron mobilization from our reserves. However, despite the fact that inflammation induces this occurrence, it can mask such results, given that ferritin - an acute phase protein, can be affected by inflammation. ${ }^{20}$ Thus, in view of the chronic inflammatory state observed in patients undergoing $\mathrm{HD}$, increased levels of ferritin are expected in these patients. During inflammation, patients are expected to have ferritin levels between $500 \mathrm{ng} / \mathrm{mL}$ and $1200 \mathrm{ng} /$ $\mathrm{mL}$, although values higher than $1200 \mathrm{ng} / \mathrm{ml}$ may be related to iron overload in patients on HD. ${ }^{21}$

It is noteworthy that, in our study, the significant contribution of ferritin to MDA levels was independent of inflammation. Furthermore, although ferritin suffers the influence of inflammation, which contributes to the need for more parameters to properly evaluate the homeostasis of iron so as to avoid overloads of this mineral in HD patients, and consequently the losses it brings about, ferritin and SatFe still represent the main parameter for assessing the iron status in the body ${ }^{11}$ and, therefore, should be considered. Thus, in view of what has been presented, it seems that in fact the studied patients had an iron overload, which in turn seems to lead to increased oxidative stress, evaluated by the MDA marker levels.

Inflammation in addition to being a factor which can influence the interpretation of body iron stores, it is also a common condition in HD patients, constituting, along with oxidative stress, another important cardiovascular risk factor, ${ }^{2}$ also associated with disease progression. ${ }^{22}$ In the present study, although most HD patients were eutrophic according to BMI, as far as body fat distribution evaluated by WC is concerned, we found that half of the patients had increased deposits of abdominal fat, which is related to inflammation and increased risk of mortality in these patients. HD patients also had elevated levels of inflammatory markers: CRP, TNF- $\alpha$ and IL- 6 compared to the control group. Thus, in view of the negative effects that inflammation and oxidative stress play in CKD, measures to minimize them are essential, and control of ferritin levels may be one of them.

An important limitation of this study is the information on the dose of iron received by patients. However, it is known that patients on HD receive constant iron supplementation. Thus, further studies in this field are needed so that we can establish a relationship between increased oxidative stress and iron supplementation. Since ferritin is an inflammation marker, we cannot state from his study whether its elevation would be associated with iron supplementation or if it only reflects the persistence of a chronic inflammatory state.

In conclusion, our results suggest that elevated ferritin levels result in increased lipid peroxidation; therefore, monitoring its levels, properly assessing the other parameters involved and administer iron carefully is crucial for HD patients to refrain from one more factor that can worsen the oxidative stress they already have.

\section{ACKNOWLEDGEMENTS}

The authors thank the Nephrology Clinic, Niterói, RJ, for allowing its patients to participate in this study; the Higher Education Personnel Improvement Coordination (CAPES), the National Research Council (CNPq) and the Foundation for Research Support of the State of Rio de Janeiro (FAPERJ) for their financial support.

\section{References}

1. Dounousi E, Papavasiliou E, Makedou A, Ioannou K, Katopodis $\mathrm{KP}$, Tselepis A, et al. Oxidative stress is progressively enhanced with advancing stages of CKD. Am J Kidney Dis 2006;48:75260. PMID: 17059994 DOI:http://dx.doi.org/10.1053/j. ajkd.2006.08.015 
2. Freigang S, Ampenberger F, Spohn G, Heer S, Shamshiev AT, Kisielow J, et al. Nrf2 is essential for cholesterol crystal-induced inflammasome activation and exacerbation of atherosclerosis. Eur J Immunol 2011;41:2040-51. DOI:http://dx.doi. org/10.1002/eji.201041316

3. Tucker PS, Dalbo VJ, Han T, Kingsley MI. Clinical and research markers of oxidative stress in chronic kidney disease. Biomarkers 2013;18:103-15. DOI:http://dx.doi.org/10.3109/1 354750X.2012.749302

4. Yilmaz MI, Saglam M, Caglar K, Cakir E, Sonmez A, Ozgurtas $\mathrm{T}$, et al. The determinants of endothelial dysfunction in CKD: oxidative stress and asymmetric dimethylarginine. Am J Kidney Dis 2006;47:42-50. PMID: 16377384 DOI:http://dx.doi. org/10.1053/j.ajkd.2005.09.029

5. Rutkowski P, Słominska EM, Szołkiewicz M, Aleksandrowicz E, Smolenski RT, Wołyniec W, et al. Relationship between uremic toxins and oxidative stress in patients with chronic renal failure. Scand J Urol Nephrol 2007;41:243-8. DOI:http:// dx.doi.org/10.1080/00365590601017170

6. Teixeira PJM. Stress oxidativo na doença renal crónica [Mestrado Integrado em Medicina]. Porto, Universidade do Porto 2010.

7. Lobo JC, Mafra D, Farage NE, Faulin Tdo E, Abdalla DS, de Nóbrega AC, et al. Increased electronegative LDL and decreased antibodies against electronegative LDL levels correlate with inflammatory markers and adhesion molecules in hemodialysed patients. Clin Chim Acta 2011;412:1788-92. PMID: 21676364 DOI:http://dx.doi.org/10.1016/j.cca.2011.05.034

8. Lim PS, Wei YH, Yu YL, Kho B. Enhanced oxidative stress in haemodialysis patients receiving intravenous iron therapy. Nephrol Dial Transplant 1999;14:2680-7. PMID: 10534512 DOI: http://dx.doi.org/10.1093/ndt/14.11.2680

9. Sengoelge G, Sunder-Plassmann G, Hörl WH. Potential risk for infection and atherosclerosis due to iron therapy. J Ren Nutr 2005;15:105-10. DOI:http://dx.doi.org/10.1053/j. jin.2004.09.018

10. Mimić-Oka J, Savić-Radojević A, Pljesa-Ercegovac M, Opacić M, Simić T, Dimković N, et al. Evaluation of oxidative stress after repeated intravenous iron supplementation. Ren Fail 2005;27:345-51.

11. KDOQI; National Kidney Foundation. KDOQI Clinical Practice Guidelines and Clinical Practice Recommendations for Anemia in Chronic Kidney Disease. Am J Kidney Dis 2006;47:S11145. PMID: 16678659

12. Obesity: preventing and managing the global epidemic. Report of a WHO consultation. World Health Organ Tech Rep Ser 2000;894:i-xii. PMID: 11234459
13. Lohman TJ, Roche AF, Martorell R, eds. Anthropometric standardization reference manual. Champaign: Human Kinetics; 1991.

14. Expert Panel on Detection, Evaluation, and Treatment of High Blood Cholesterol in Adults. Executive Summary of The Third Report of The National Cholesterol Education Program (NCEP) Expert Panel on Detection, Evaluation, And Treatment of High Blood Cholesterol In Adults (Adult Treatment Panel III). JAMA 2001;285:2486-97. DOI: http://dx.doi. org/10.1001/jama.285.19.2486

15. Ohkawa H, Ohishi N, Yagi K. Assay for lipid peroxides in animal tissues by thiobarbituric acid reaction. Anal Biochem 1979;95:351-8. DOI:http://dx.doi.org/10.1016/00032697(79)90738-3

16. Senol E, Ersoy A, Erdinc S, Sarandol E, Yurtkuran M. Oxidative stress and ferritin levels in haemodialysis patients. Nephrol Dial Transplant 2008;23:665-72. DOI: http://dx.doi. org/10.1093/ndt/gfm588

17. Almeida SG, Veiga JP, Arruda SF, Neves CF, Siqueira EM. The association of markers of oxidative-inflammatory status with malnutrition in hemodialysis patients with serum ferritin lower than $500 \mathrm{ng} / \mathrm{mL}$. J Bras Nefrol 2013;35:6-12. DOI: http:// dx.doi.org/10.5935/01012800.20130002

18. Van Campenhout A, Van Campenhout C, Lagrou A, Manuel$\mathrm{y}$-Keenoy B. Iron-induced oxidative stress in haemodialysis patients: a pilot study on the impact of diabetes. Biometals 2008;21:159-70. DOI: http://dx.doi.org/10.1007/s10534-0079104-9

19. Lobo JC, Farage NE, Abdalla DS, Velarde LG, Torres JP, Mafra D. Association between circulating electronegative low-density lipoproteins and serum ferritin in hemodialysis patients: a pilot study. J Ren Nutr 2012;22:350-6. DOI:http://dx.doi. org/10.1053/i.jrn.2011.05.002

20. Abensur H. Deficiência de ferro na doença renal crônica. Rev Bras Hematol Hemoter 2010;32:95-8. DOI: http://dx.doi. org/10.1590/S1516-84842010005000047

21. Kalantar-Zadeh K, Streja E, Miller JE, Nissenson AR. Intravenous iron versus erythropoiesis-stimulating agents: friends or foes in treating chronic kidney disease anemia? Adv Chronic Kidney Dis 2009;16:143-51. PMID: 19233073

22. Shankar A, Sun L, Klein BE, Lee KE, Muntner P, Nieto FJ, et al. Markers of inflammation predict the long-term risk of developing chronic kidney disease: a population-based cohort study. Kidney Int 2011;80:1231-8. PMID: 21866089 DOI:http:// dx.doi.org/10.1038/ki.2011.283 